Check for updates

Cite this: RSC Adv., 2018, 8, 5902

\title{
Manganese(II) enhanced fluorescent nitrogen- doped graphene quantum dots: a facile and efficient synthesis and their applications for bioimaging and detection of $\mathrm{Hg}^{2+}$ ions $\dagger$
}

\begin{abstract}
Li Yang, ${ }^{a}$ Aimiao Qin, (D) *a Shuoping Chen, ${ }^{a}$ Lei Liao, ${ }^{a}$ Jiangke Qin ${ }^{b}$ and Kaiyou Zhang ${ }^{a}$
Manganese ion $\left(\mathrm{Mn}^{2+}\right)$ bonded nitrogen-doped graphene quantum dots ( $\mathrm{Mn}(I)$-NGQDs) with water solubility have been successfully synthesized by a simple, one-pot hydrothermal carbonization, using sodium citrate, glycine and manganese chloride as raw materials. The photoluminescence (PL) characteristics of Mn(॥)-NGQDs were studied in detail. The resulting Mn(॥)-NGQDs show a remarkably enhanced PL intensity and quantum yield (QY $=42.16 \%$ ) compared with the product without $\mathrm{Mn}(\mathrm{I})$ doped (named as NG, QY $=27.06 \%$ ) and the product doped with other metal ions. The Mn(॥)-NGQDs not only display low toxicity and high cellular uptake efficiency for fluorescence live cell imaging in biological evaluations but also exhibit a fast, highly selective and sensitive fluorescence quenching effect toward $\mathrm{Hg}^{2+}$ ions, with a detection limit of $3.4 \times 10^{-8} \mathrm{~mol} \mathrm{~L}^{-1}$.
\end{abstract}

Received 4th November 2017 Accepted 31st January 2018

DOI: 10.1039/c7ra12133d

rsc.li/rsc-advances
To date, a myriad of strategies for fabricating GQDs and graphene derivatives have been explored, such as pyrolysis synthesis, ${ }^{\mathbf{1 4}}$ electrochemical synthesis, ${ }^{\mathbf{1 5}}$ microwave-assisted solid-phase synthesis, ${ }^{\mathbf{1 6}}$ hydrothermal synthesis $^{\mathbf{1 7}}$ and etc. Among these synthesis approaches, the carbonization of citric acid to prepare GQDs were considered to be one of promising method, since it can provide stable quantum dots with high yields. ${ }^{18,19}$ However, there are a series of problems for the direct carbonization of citric acid to face, such as complicated preparation process, harsh reaction conditions (such as strong acid/ alkali using), accurate $\mathrm{pH}$ control and tedious postprocessing, which may lead to great restrictions for the further biomedical applications of QDs. ${ }^{20-22}$

To extend and improve the physical and chemical properties of GQDs, different modification methods have been applied, including surface functional groups modification, ${ }^{23}$ heteroatoms doping ${ }^{24,25}$ and formation of composite. ${ }^{26,27}$ For example, the ways of functionalization with surface groups and heteroatoms doping (such as $\mathrm{N}, \mathrm{S}$ ) may significantly transform the optical properties, quantum yields, chemical activities and electronics structure of GQDs, ${ }^{\mathbf{2 8 , 2 9}}$ which would provide interesting luminescent properties, such as $\mathrm{pH}$-dependent and excitation-dependent photoluminescence (PL) behaviors. ${ }^{30,31}$ The interaction of GQDs and metal ions or rare earth elements $^{32,33}$ in solution may lead to the excitation/emission spectrum suppression, amplification or shift, which has been used for high selectivity and sensitivity detection of different ions and specificity molecules. Han et al. reported the magneticfluorescent imaging behavior based on manganese(II)-carbon
${ }^{a}$ Key Lab New Processing Technology for Nonferrous Metals \& Materials, Ministry of Education, Guangxi Key Laboratory in Universities of Clean Metallurgy and Comprehensive Utilization for Non-ferrous Metals Resources, College of Materials Science \& Engineering, Guilin University of Technology, Guilin, China. E-mail: 592491245@qq.com

${ }^{b}$ College of Chemistry and Pharmaceutical Science, Guangxi Normal University, Guilin, China

$\dagger$ Electronic supplementary information (ESI) available. See DOI: 10.1039/c7ra12133d 
dots, indicating that the metal bonded GQDs could be good fluorescent probes for bioimaging. ${ }^{34}$

In this paper, in order to explore the doping effect of different metal ions on the PL behaviors of GQDs, we chose sodium citrate and glycine as carbon and nitrogen sources respectively to synthesize multifunctional GQDs for the first time. By using the facile and efficient hydrothermal method, $\mathrm{Mn}^{2+}$ bonded nitrogen-doped graphene quantum dots (Mn(II)NGQDs) with water solubility and multifunction were successfully produced, which is the first case of Mn(II)-NGQDs with $\mathrm{Mn}^{2+}$ enhanced fluorescence via a confinement effect between $\mathrm{Mn}^{2+}$ and functional groups. The Mn(II)-NGQDs exhibit a strong emission with high quantum yield, and display a highly selective and sensitive fluorescence quenching response to $\mathrm{Hg}^{2+}$. Moreover, the Mn(II)-NGQDs show low cytotoxicity and are suitable for fluorescence live cell imaging, which would be used for bio-imaging application.

\section{Experimental}

\section{Reagents and chemicals}

Glycine, sodium citrate, $\mathrm{MnCl}_{2} \cdot 4 \mathrm{H}_{2} \mathrm{O}, \mathrm{MnSO}_{4}, \mathrm{Mn}\left(\mathrm{NO}_{3}\right)_{2}$, $\mathrm{Mn}\left(\mathrm{CH}_{3} \mathrm{COO}\right)_{2}, \mathrm{Ni}\left(\mathrm{NO}_{3}\right)_{2} \cdot 6 \mathrm{H}_{2} \mathrm{O}, \mathrm{Pb}\left(\mathrm{NO}_{3}\right)_{2}, \mathrm{AgNO}_{3}, \mathrm{Zn}\left(\mathrm{NO}_{3}\right)_{2}-$ $\cdot 6 \mathrm{H}_{2} \mathrm{O}, \quad \mathrm{CuCl}_{2} \cdot 2 \mathrm{H}_{2} \mathrm{O}, \quad \mathrm{FeSO}_{4} \cdot 7 \mathrm{H}_{2} \mathrm{O}, \quad \mathrm{FeCl}_{3} \cdot 6 \mathrm{H}_{2} \mathrm{O}, \mathrm{Co}\left(\mathrm{NO}_{3}\right)_{2^{-}}$ $\cdot 6 \mathrm{H}_{2} \mathrm{O}, \mathrm{CaCl}_{2}, \mathrm{CdCl}_{2}$, hexamethylenetetramine (HMTA) and other chemicals were of analytical grade and used as received without further purification. Milli-Q water $(18.2 \mathrm{M} \Omega$ ) was used for all of the experiments. Stock solutions of $\mathrm{Hg}^{2+}, \mathrm{Ag}^{+}, \mathrm{Al}^{3+}$, $\mathrm{Ba}^{2+}, \mathrm{Cr}^{3+}, \mathrm{Ca}^{2+}, \mathrm{Cd}^{2+}, \mathrm{Co}^{2+}, \mathrm{Cu}^{2+}, \mathrm{Fe}^{2+}, \mathrm{Fe}^{3+}, \mathrm{Mg}^{2+}, \mathrm{Mn}^{2+}, \mathrm{Zn}^{2+}$, $\mathrm{Ni}^{2+}$ and $\mathrm{Pb}^{2+}$ ions were prepared by dissolving corresponding metal salts in Milli-Q water.

\section{Characterization}

Transmission electron microscopy (TEM) was carried out on a JEOL-2010 TEM at $200 \mathrm{kV}$. Fourier transform infrared (FTIR) spectra were recorded using a FTIR2500 spectrometer ( $\mathrm{KBr}$ disk). Raman spectra were collected on a LabRam-1B Raman spectroscope equipped with a $632.8 \mathrm{~nm}$ laser source. X-ray diffraction spectra (XRD) were determined on a Holland PANalytical X'Pert PRO X-ray diffractometer with $\mathrm{Cu} \mathrm{K} \alpha(\lambda=$ $1.54056 \AA$ A ) as radiation source in the $2 \theta$ range of $5-80^{\circ}$. X-ray photoelectron spectroscopy (XPS) measurements were made on Kratos AXIS UltraDLD (Kratos Analytical Ltd.) with mono Al $\mathrm{K} \alpha$ radiation $(h \nu=1487.71 \mathrm{eV})$ at a power of $75 \mathrm{~W}$. Emission spectra were collected using a Varian Cary 100 spectrometer. Fluorescence life time of the products were determined using a FLS980 fluorometer (Edinburgh Instruments Ltd.). Absorption spectra were recorded on a UV-3600 UV-vis-NIR spectrophotometer (Shimadzu). Fluorescence quantum yield (QY) was detected using quinine sulfate as the standard $(\mathrm{QY}=54 \%$ in $0.1 \mathrm{M} \mathrm{H}_{2} \mathrm{SO}_{4}$ ). Confocal laser-scanning microscopy (CLSM) images were recorded on a Zeiss LSM 710 CLSM (Zeiss LSM710, Germany). The zeta potential of Mn(II)-NGQDs and NG were measured by a Zetasizer Nano ZS90 (Malvern Instruments).

\section{Synthesis of Mn(II)-NGQDs and NG}

In typically synthesis, a mixture of glycine $(0.0451 \mathrm{~g})$, sodium citrate solution $\left(12 \mathrm{~mL}, 0.1 \mathrm{~mol} \mathrm{~L}^{-1}\right), \mathrm{MnCl}_{2}$ solution $(1 \mathrm{~mL}$, $\left.0.1 \mathrm{~mol} \mathrm{~L}^{-1}\right)$ and Milli-Q water $(37 \mathrm{~mL})$ was added into a flask with stirring, to form a clear reaction solution. The solution was then transferred into a $100 \mathrm{~mL}$ Teflon-lined autoclave, and then heated to $180^{\circ} \mathrm{C}$ for $10 \mathrm{~h}$. After that, the autoclave was cooled down naturally to room temperature. The obtained bright transparent solution was centrifuged at $10000 \mathrm{rpm}$ for $10 \mathrm{~min}$ to remove the deposit. Subsequently, the supernatant of $\mathrm{Mn}$ (II)NGQDs solution (6.52 $\mathrm{mg} \mathrm{mL}^{-1}$, ESI $\dagger$ ) was dialyzed (molecular weight cut off, $1000 \mathrm{Da}$ ) against water for $48 \mathrm{~h}$. Afterwards, the pure and solid-state Mn(II)-NGQDs white powder was obtained by vacuum freeze drying. Finally, the resulted Mn(II)-NGQDs were dispersed in water as a stock solution for further characterization and detection.

As a contrast, other common metal ions doped in NG (M$\mathrm{NG}, \mathrm{M}=\mathrm{Ag}^{+}, \mathrm{Al}^{3+}, \mathrm{Ba}^{2+}, \mathrm{Cr}^{3+}, \mathrm{Ca}^{2+}, \mathrm{Cd}^{2+}, \mathrm{Co}^{2+}, \mathrm{Cu}^{2+}, \mathrm{Fe}^{2+}, \mathrm{Fe}^{3+}$, $\mathrm{K}^{+}, \mathrm{Mg}^{2+}, \mathrm{Zn}^{2+}, \mathrm{Ni}^{2+}$ or $\mathrm{Pb}^{2+}$ ), were also prepared using the similar method as Mn(II)-NGQDs, except for using different metal salts. In addition, the NG without metal doping was also prepared using the above experimental procedure.

\section{Fluorescence detection of $\mathbf{H g}^{2+}$ ion}

In a typical process, $200 \mu \mathrm{L}$ of $\mathrm{Hg}^{2+}$ solution with various concentrations $\left(0-5 \times 10^{-6} \mathrm{~mol} \mathrm{~L}^{-1}\right)$ and $200 \mu \mathrm{L}$ of $\mathrm{Mn}(\mathrm{II})$ NGQDs $\left(6.52 \mathrm{mg} \mathrm{mL}^{-1}\right)$ solution were mixed together and diluted to $5 \mathrm{~mL}$ with the HMTA buffer solution ( $\mathrm{pH}=7.35$ ). After kept at room temperature for $10 \mathrm{~min}$, the fluorescence emission spectra of the solution were collected under an excitation wavelength of $370 \mathrm{~nm}$. As a contrast, the sensing capability of NG toward $\mathrm{Hg}^{2+}$ have been investigated by a same detection procedure. The procedure of Mn(II)-NGQDs detection of $\mathrm{Hg}^{2+}$ in Milli-Q water were also carried out.

\section{Cellular toxicity test}

The cytotoxicity of Mn(II)-NGQDs was evaluated by the MTT assay. HepG2 human liver cancer cells were harvested (obtained from Shanghai Institute of Organic Chemistry, Chinese Academy of Sciences; the cell density was adjusted to $10^{5}$ cells per $\mathrm{mL}$ ) and seeded in a 96-well plate overnight for $24 \mathrm{~h}$. Then, the Mn(II)-NGQDs solution was added into each well with increasing concentrations from 0 to $300 \mu \mathrm{g} \mathrm{mL}{ }^{-1}$. After that, the cells were cultivated for 4 and $24 \mathrm{~h}$, respectively. And then, $10 \mu \mathrm{L}$ of $5 \mathrm{mg} \quad \mathrm{mL}^{-1}$ MTT (3-(4,5-dimethylthiazol-2-yl)-2,5diphenyltetra-zolium bromide) solution was added to each cell well. After incubation for $4 \mathrm{~h}$, the culture medium was discarded, and $100 \mu \mathrm{L}$ of dimethyl sulfoxide (DMSO) was added. The obtained mixture was shaken for $15 \mathrm{~min}$ in the dark at room temperature, and the absorbance of each well was measured at wavelength of $570 \mathrm{~nm}$ using an enzyme linked immunosorbent assay (Tecan Infinite M1000) reader with pure DMSO as a blank. In addition, HepG2 human liver cancer cells without Mn(II)-NGQDs treating were used as a control to test their relative cell viability. 


\section{Live cell imaging}

HepG2 human liver cancer cells and Raw264.7 mouse macrophages (obtained Shanghai, China) were cultured in Dul-becco's modified eagle medium (DMEM) supplemented with $\mathrm{PBS}$ ( $\mathrm{pH}=$ 7.4) in $10 \%$ and $100 \mathrm{mg} \mathrm{mL} \mathrm{m}^{-1}$ streptomycin and 100 units per $\mathrm{mL}$ penicillin solution in $5 \% \mathrm{CO}_{2}$ at $37{ }^{\circ} \mathrm{C}$. The cells were grown on the bottom of $35 \mathrm{~mm}$ glass culture dishes to the density of $80 \%$ confluence and then incubated with $\mathrm{Mn}$ (II)NGQDs at $37^{\circ} \mathrm{C}$ for $3 \mathrm{~h}$. Then, the cells were washed three times with PBS. Images of the cells were immediately captured at ambient temperature on a laser scanning confocal microscopy using a digital camera.

\section{Results and discussion}

\section{Characterization of Mn(II)-NGQDs}

The synthetic procedure for the fabrication of fluorescent Mn(II)-NGQDs is illustrated in Fig. 1. The morphology and microstructure of the Mn(II)-NGQDs were confirmed by the typical TEM image. As shown in Fig. 2a, the Mn(II)-NGQDs were well dispersed and uniform in size and shape. The corresponding size distribution histogram was obtained by random counting 100 particles (Fig. S1, ESI $\dagger$ ), indicating that the size of $\mathrm{Mn}$ (II)-NGQDs was about 1.0-5.5 $\mathrm{nm}$ with an average diameter of approximately $4.5 \mathrm{~nm}$. By contrast, the NG consisted of a large amounts of irregular nanosheets and a small amount of QDs (Fig. 2b, ESI $\dagger$ ). Obviously, the bonding of $\mathrm{Mn}^{2+}$ can change the morphology of NG effectively. The HRTEM image of the Mn(II)-NGQDs shows their well-resolved lattice fringes, which indicates that they possess relatively good crystallinities. The lattice spacings of Mn(II)-NGQDs (the inset in Fig. 2a) and NG (the inset in Fig. 2b) are 0.24 and $0.26 \mathrm{~nm}$ respectively, which are assigned to the (100) and (020) plane of graphitic carbon, respectively. ${ }^{35}$

According to the XRD patterns of Mn(II)-NGQDs and NG (Fig. S2, ESI $\dagger$ ), both of Mn(II)-NGQDs and NG exhibit two broad peaks centered at $9.2^{\circ}(2 \theta)$ and $31.5^{\circ}(2 \theta)$, corresponding to the (001) and (002) plane of graphitic nitride carbon, ${ }^{36,37}$ respectively. Compared with NG, the board peak at $31.5^{\circ}(2 \theta)$ of $\mathrm{Mn}$ (II)NGQDs is weakened obviously, indicating that in $\mathrm{Mn}$ (II)NGQDs, the $\mathrm{Mn}^{2+}$ ions bond with the functional groups at the edge of NG, and may help to divide the large graphene sheets to small graphene domains.

Fig. 3a shows the FTIR spectra of Mn(II)-NGQDs and NG. The broad band at $3406 \mathrm{~cm}^{-1}$ corresponds to the stretching vibration of $\mathrm{O}-\mathrm{H}$ and $\mathrm{N}-\mathrm{H}$. The strong and broad absorption band ranging from $1500 \mathrm{~cm}^{-1}$ to $1750 \mathrm{~cm}^{-1}$ with a center at $1580 \mathrm{~cm}^{-1}$ corresponded to the stretching vibrations of $\mathrm{C}=\mathrm{O}$ and $\mathrm{C}=\mathrm{C}$ in the aromatic ring. The bands at $1407 \mathrm{~cm}^{-1}$ and $830 \mathrm{~cm}^{-1}$ were assigned to the $\mathrm{C}-\mathrm{H}$ bending and $\mathrm{C}-\mathrm{H}$ stretching, respectively. The bands at $1258 \mathrm{~cm}^{-1}$ and $1078 \mathrm{~cm}^{-1}$ were attributed to the stretching vibrations of $\mathrm{O}-\mathrm{H}$ and $\mathrm{C}-\mathrm{O}-\mathrm{C}$, respectively. ${ }^{16,38,39}$ The small peaks at $1495 \mathrm{~cm}^{-1}$ and $1449 \mathrm{~cm}^{-1}$ corresponded to the $\mathrm{NH}_{3}{ }^{+}$symmetric bending and $\mathrm{C}-\mathrm{N}$ stretching vibration, respectively, ${ }^{39,40}$ which confirmed that nitrogen atoms have been successfully doped into the Mn(II)NGQDs and NG. However, compared to NG, the C-O stretching vibration at $1078 \mathrm{~cm}^{-1}$ and $\mathrm{NH}_{3}{ }^{+}$symmetric bending at $1495 \mathrm{~cm}^{-1}$ in $\mathrm{Mn}$ (II)-NGQDs disappear, indicating the existence of $\mathrm{Mn}^{2+}$ ions which have bonded to the NG. Moreover, the C-N stretching vibration of Mn(II)-NGQDs at $1449 \mathrm{~cm}^{-1}$ increases obviously, indicates that more nitrogen elements are preserved after the coordination effect of $\mathrm{Mn}^{2+}$ ions. Fig. 3b shows the

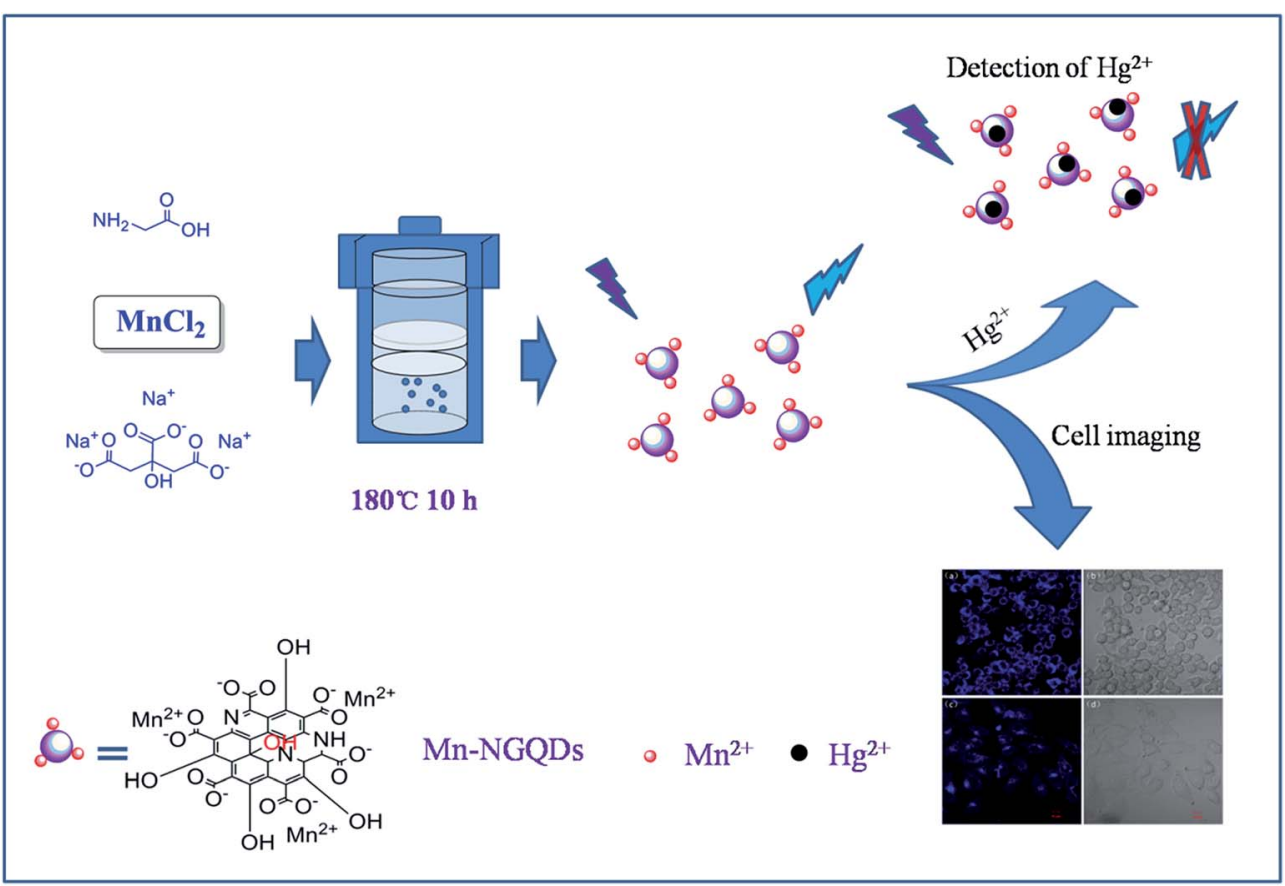

Fig. 1 Schematic illustration of the synthesis of $\mathrm{Mn}(\mathrm{II})-\mathrm{NGQDs}$ and cells imaging and $\mathrm{Hg}^{2+}$ detection. 


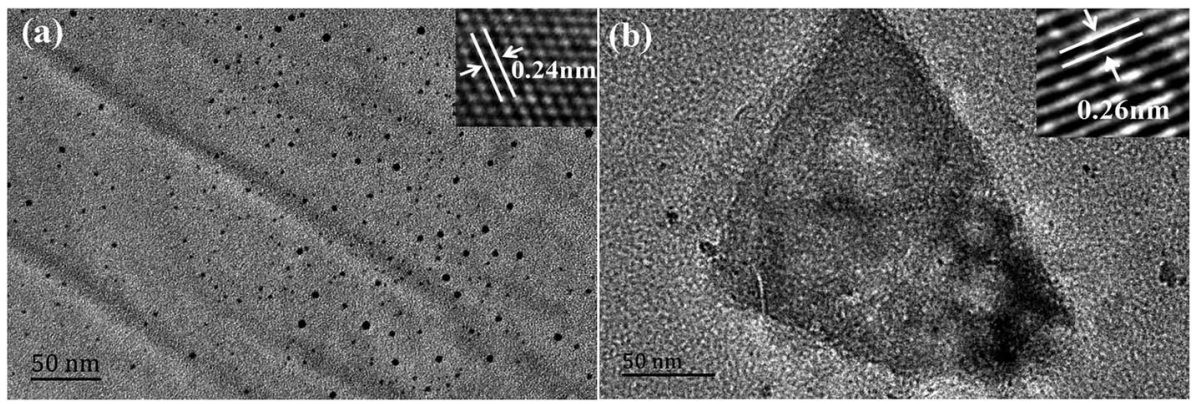

Fig. 2 TEM and HRTEM images of (a) Mn(॥)-NGQDs and (b) NG.
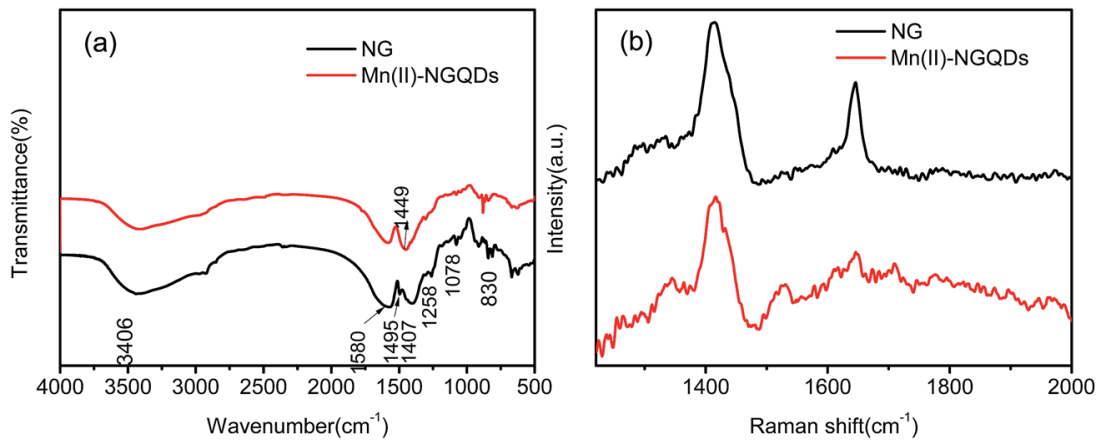

Fig. 3 (a) FT-IR spectra of Mn(॥)-NGQDs and NG; (b) Raman spectrum of Mn(॥)-NGQDs and NG.

Raman spectra of Mn(II)-NGQDs and NG. Both of Mn(II)-NGQDs and NG demonstrate a $\mathrm{G}$ band at $1645 \mathrm{~cm}^{-1}$, which relates to the vibration of the $\mathrm{sp}^{2}$ hybridization of graphitic carbon, and a D band at $1411 \mathrm{~cm}^{-1}$, which corresponds to the carbon lattice distortion. Compared to NG, Mn(II)-NGQDs show a more weak G band at $1645 \mathrm{~cm}^{-1}$ and a larger intensity ratio $I_{\mathrm{D}} / I_{\mathrm{G}}$ increase from 1.29 to 2.23 . Similar to the previous analysis, ${ }^{41-43}$ more structural defects, larger $\mathrm{sp}^{2}$ domains and smaller $\mathrm{sp}^{2}$ fragments are expected to be present in the Mn(II)-NGQDs. It is indicated that the bonding of $\mathrm{Mn}^{2+}$ can change the morphology of $\mathrm{NG}$.

Furthermore, more information of the surface functional groups of Mn(II)-NGQDs and NG is further provided by XPS analysis (Fig. 4). The full-range spectra (Fig. 4a) show that, both of Mn(II)-NGQDs and NG contain C, N and O elements, and there is about $0.21 \% \mathrm{Mn}$ (atomic fraction) in Mn(II)-NGQDs (Table S1, ESI $\dagger$ ). Fig. 4b shows the C 1s XPS spectrum of the Mn(II)-NGQDs, which ranged from 280 to $292 \mathrm{eV}$. There are four adjacent peaks at $284.3 \mathrm{eV}, 284.9 \mathrm{eV}, 285.9 \mathrm{eV}$ and $288.1 \mathrm{eV}$, which can be attributed to $\mathrm{C}-\mathrm{C} / \mathrm{C}=\mathrm{C}, \mathrm{C}-\mathrm{N}, \mathrm{C}-\mathrm{O}$ and $\mathrm{C}=\mathrm{O}$ bonding respectively. ${ }^{9}$ The $\mathrm{N}$ 1s spectrum of Mn(II)-NGQDs (Fig. 4d) exhibits three peaks at $398.9 \mathrm{eV}, 399.2 \mathrm{eV}$ and $400.9 \mathrm{eV}$, which are associated with $\mathrm{C}-\mathrm{N}-\mathrm{C}, \mathrm{N}-(\mathrm{C})_{3}$ and $\mathrm{N}-\mathrm{H}$ groups. ${ }^{\mathbf{1 1 , 3 9 , 4 0}}$ The O 1s spectra of Mn(II)-NGQDs (see Fig. S3a, ESI $\dagger$ ) and NG (see Fig. S3b, ESI $\dagger$ ) show two peaks at $531.0 \mathrm{eV}$ and $531.8 \mathrm{eV}$, which are associated with $\mathrm{O}-\mathrm{H}$ and $\mathrm{C}-\mathrm{O}-\mathrm{C}$ groups, respectively. ${ }^{17}$ These spectra reveals that nitrogen element has successfully introduced into the Mn(II)-NGQDs and NG, and Mn(II)-NGQDs and NG has been functioned with some groups, such as $-\mathrm{COOH},-\mathrm{OH}$ and $\mathrm{N}-\mathrm{H}$ group. The high resolution XPS spectrum of Mn 2p (Fig. 4b) shows a dominant peak at $641 \mathrm{eV}$ assigned to $\mathrm{Mn}^{2+}$, indicating that the oxidation state of $\mathrm{Mn}$ on the surface of Mn(II)-NGQDs remains unchanged. ${ }^{34}$ Compared to the XPS spectrum of NG, the C 1s (Fig. 4e) and N 1s (Fig. 4f) spectra of Mn(II)-NGQDs in the peak shape are very similar to those of NG, which means that the introduction of $\mathrm{Mn}^{2+}$ ions cannot affect the carbon-based species. However, the atomic fraction (Table $\mathrm{S} 1, \mathrm{ESI} \dagger$ ) of $\mathrm{N}$ in $\mathrm{Mn}(\mathrm{II})$-NGQDs $(4.24 \%)$ is dramatically increasing compared with that of NG $(2.2 \%)$, which may indicate that more $\mathrm{N}-\mathrm{H}$ groups are preserved by the coordination effect of $\mathrm{Mn}^{2+}$ ion. The above results clearly reveal that Mn(II)-NGQDs and NG have been successfully produced.

\section{Optical properties}

In order to investigate the optical properties of the as-prepared Mn(II)-NGQDs, the excitation, emission and UV-vis absorption spectra were studied and the results are given in Fig. 5a. The UVvis absorption spectrum of Mn(II)-NGQDs shows two main absorption peaks: one peak centered at $260 \mathrm{~nm}$ is attributed to $\pi-\pi^{*}$ transition of $\mathrm{C}-\mathrm{C}$ band, and the other centered at $340 \mathrm{~nm}$ can be ascribed to the $\mathrm{n}-\pi^{*}$ transition of $\mathrm{C}-\mathrm{N}$ and $\mathrm{C}=\mathrm{O}$ groups. ${ }^{44} \mathrm{NG}$ and other M-NG also display the two peaks which are similar to Mn(II)-NGQDs (Fig. S4, ESI $\dagger$ ). As shown in Fig. 5a, the maximum excitation wavelength $(370 \mathrm{~nm})$ of Mn(II)-NGQDs gets a red shift than the UV-vis absorption band (340 nm), which can be ascribed to a distribution of the deferent surface energy traps of the carbon dots. The emission wavelength $\left(\lambda_{\mathrm{em}}=443\right)$ of Mn(II)-NGQDs has no obvious change, compared with NG, 

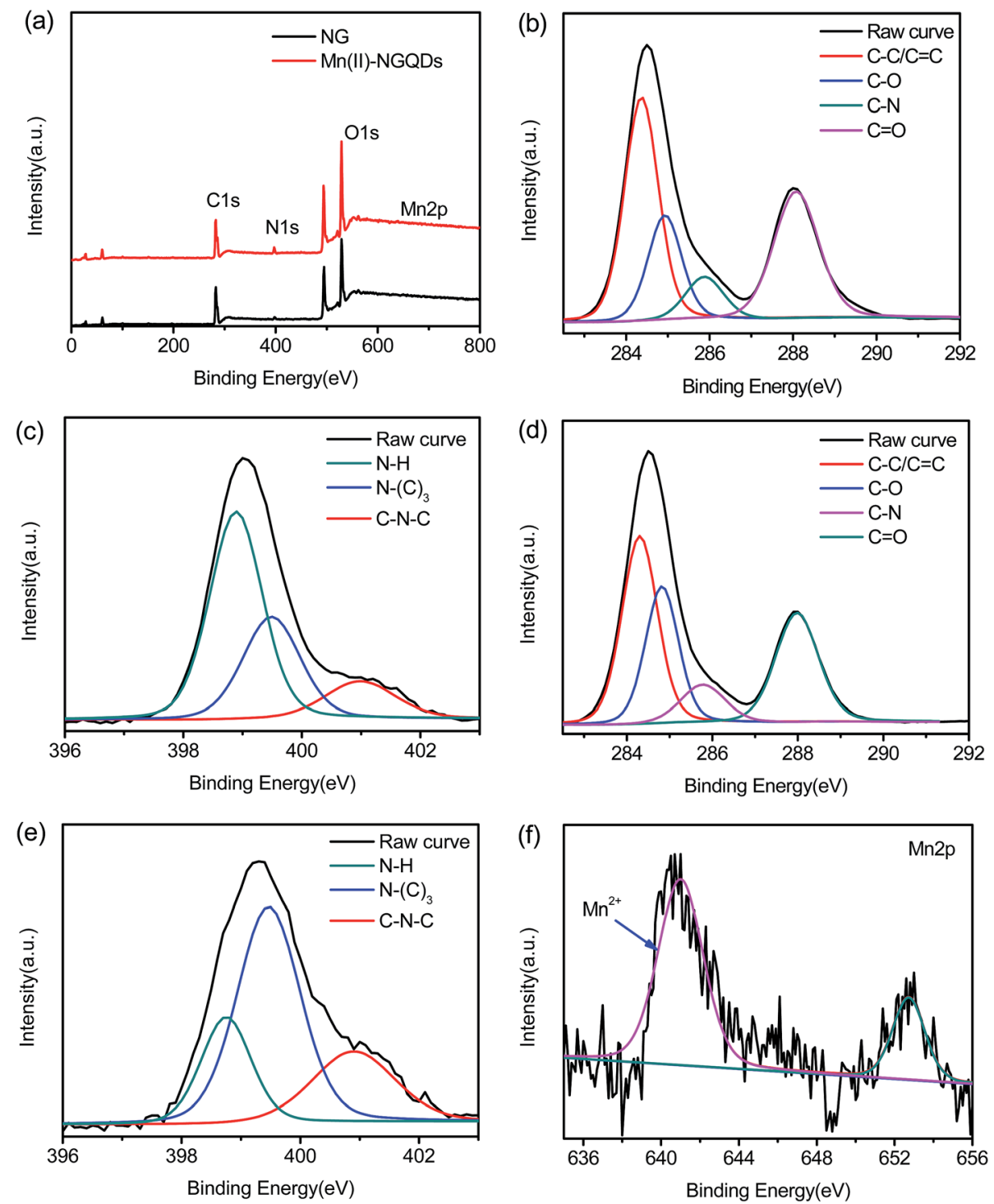

Fig. 4 (a) XPS survey spectra of Mn(॥)-NGQDs and NG; (b) C 1s and (c) N 1s region of Mn(॥)-NGQDs, (d) C 1s and (e) N 1s region of NG; XPS high resolution of (f) $M n$ 2p.

but the fluorescence intensity of Mn(II)-NGQDs shows much stronger than that of NG. Fig. 5b shows that the emission spectra of Mn(II)-NGQDs have an excitation independent feature as the excitation wavelength gradually increases from 350$400 \mathrm{~nm}$, with the maximum excitation wavelength and the maximum emission wavelength at 370 and $443 \mathrm{~nm}$, respectively. The excitation independent phenomenon were also observed in previous reported, ${ }^{19,22}$ which may be due to the uniform size of Mn(II)-NGQDs and the unitary PL process of $n$ $\pi^{*}$ transition of the aromatic $\mathrm{N}$ in Mn(II)-NGQDs. Fig. 5c and d show the emission spectra and QY of Mn(II)-NGQDs with different concentrations of $\mathrm{Mn}^{2+}$ ion in reaction system under the excitation wavelength of $370 \mathrm{~nm}$. The results indicate that the strongest synergistic effect with functional groups in reaction systems appears at the concentration $\mathrm{Mn}^{2+}$ ion of $2 \times$ $10^{-3} \mathrm{~mol} \mathrm{~L}^{-1}$. The highest fluorescence QY of the obtained Mn(II)-NGQDs was determined to be $42.16 \%$, which is much higher than that of NG $(27.06 \%)$ and the previous report of $\mathrm{N}$ GQDs $(28.10 \%) .{ }^{39}$ This implied that the induced $\mathrm{Mn}^{2+}$ into NG significantly enhanced the fluorescence QY of NG.

To further confirm that the enhanced PL indeed arises from the $\mathrm{Mn}^{2+}$-assisted process, the control experiments were carried out by utilizing other Mn salts to replace manganese chloride, including manganese acetate, manganese sulfate and manganese nitrate, the results show that they can still enhance the fluorescence (Fig. S5a, ESI $\dagger$ ), indicating that $\mathrm{Mn}^{2+}$ plays a key role in the enhanced PL from the Mn(II)-NGQDs. Furthermore, holding any other factors constant, citric acid was chosen to replace citric sodium as carbon precursor to prepare $\mathrm{Mn}$ (II)NGQDs and NG for comparison. The comparison experiment results show that, choosing citric acid as precursor for high quality fluorescent quantum dots is unsuitable (Fig. S5b, ESI†). This indicates that citric sodium precursor also plays an important role in the improved PL of Mn(II)-NGQDs. 

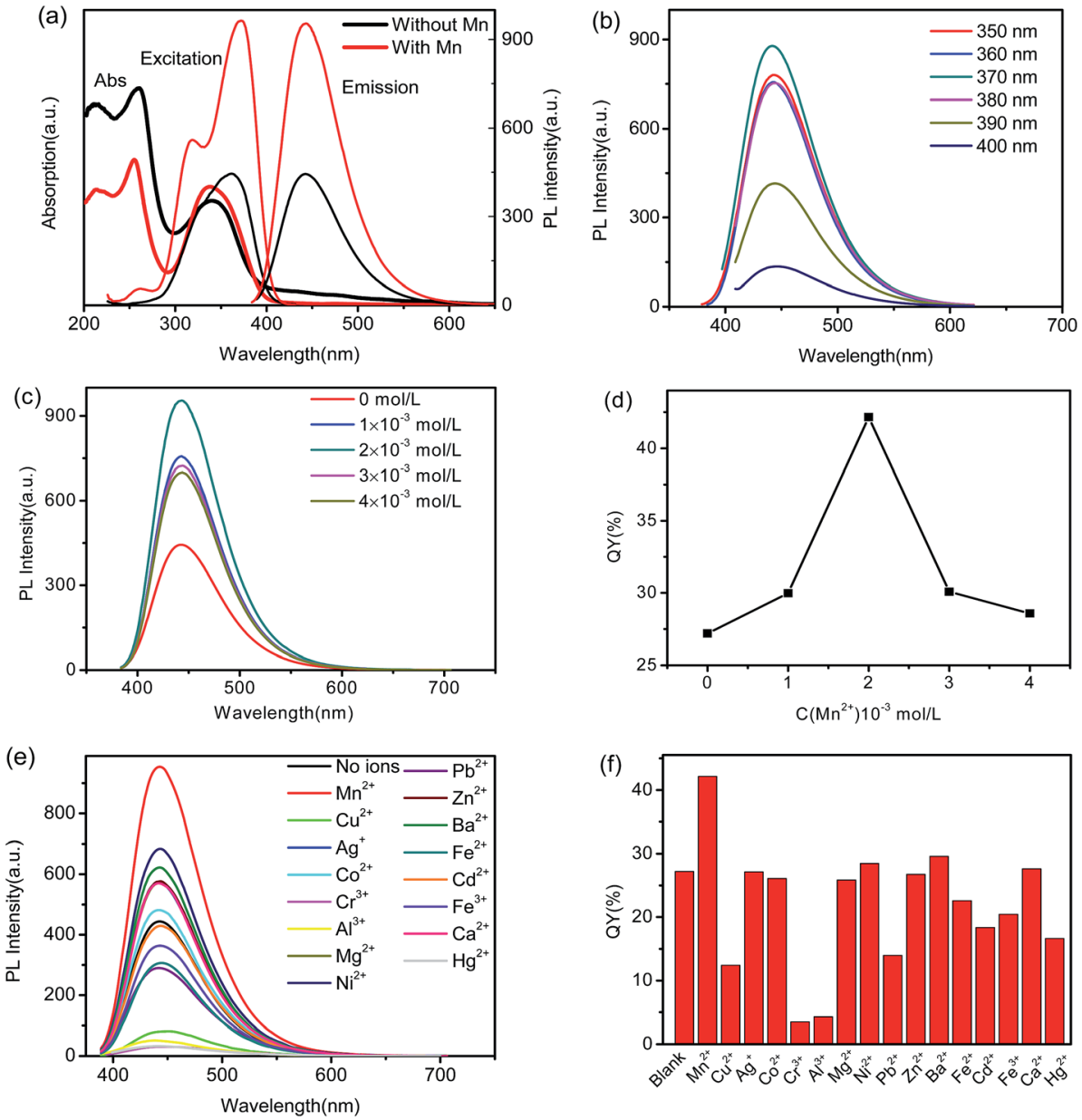

Fig. 5 (a) UV-Vis absorption and PL spectra $\left(\lambda_{\text {ex }}=370 \mathrm{~nm}\right.$ ) of Mn(॥)-NGQDs and NG; (b) PL spectra of Mn(॥)-NGQDs recorded for progressively longer excitation wavelengths from 350 to $400 \mathrm{~nm}$; (c) the effect of $\mathrm{Mn}^{2+}$ doping concentrations on the PL spectra ( $\lambda_{\text {ex }}=370 \mathrm{~nm}$ ) of $\mathrm{Mn}(\|)$ NGQDs; (d) the effect of $\mathrm{Mn}^{2+}$ doping concentrations on the QY of Mn(॥)-NGQDs; (e) the effect of common metal ions doping on the PL spectra of NG; (f) the effect of common metal ions doping on the QY of NG.

The as-synthesized Mn(II)-NGQDs also exhibit a good stability (Fig. S5c, ESI $\dagger$ ). The PL spectra of the Mn(II)-NGQDs are almost the same with the fresh Mn(II)-NGQDs after 7 days of storage under ambient conditions. In addition, the synergy process of $\mathrm{Mn}^{2+}$ ion with functional groups would also be influenced by the reaction temperature (Fig. S5d, ESI $\dagger$ ) and time, the optimum hydrothermal temperature and time were considered as $180^{\circ} \mathrm{C}$ and 10 hours, respectively.

Fig. 5e and $f$ show the PL spectra and QYs of various M-NG. All of the other M-NG display a weaker emission behavior compared to Mn(II)-NGQDs (Fig. 5e). Fig. $5 \mathrm{f}$ indicates that the QYs of seven kinds of $\mathrm{M}^{\prime}-\mathrm{NG}\left(\mathrm{M}^{\prime}=\mathrm{Ni}^{2+}, \mathrm{Mg}^{2+}, \mathrm{Zn}^{2+}, \mathrm{Ba}^{2+}, \mathrm{Co}^{2+}\right.$, $\mathrm{Ag}^{+}$and $\left.\mathrm{Ca}^{2+}\right)$ are similar to that of NG, while other seven kinds of $\mathrm{M}^{\prime \prime}-\mathrm{NG}\left(\mathrm{M}^{\prime \prime}=\mathrm{Cu}^{2+}, \mathrm{Cr}^{2+}, \mathrm{Cd}^{2+}, \mathrm{Fe}^{2+}, \mathrm{Fe}^{3+}, \mathrm{Al}^{3+}\right.$ and $\left.\mathrm{Pb}^{2+}\right)$ have much lower QYs than that of NG.

Why only the introduction of $\mathrm{Mn}^{2+}$ ion into NG can obviously enhance their fluorescence? The mechanism is conjectured as the follows: in the hydrothermal reaction of glycine and sodium citrate, parts of carboxyl groups of sodium citrate may not be carbonized and retain on the surface of NG. These carboxyl groups have high reactivity for further condensation and carbonization, that is why a large amount of irregular graphene nanosheets and some agglomeration were observed in NG samples without $\mathrm{Mn}^{2+}$ doping. These irregular graphene nanosheets and large particles would reduce the fluorescent emission behavior. However, in the reaction process of Mn(II)-NGQDs, $\mathrm{Mn}^{2+}$ ions can bond with functional groups such as carboxyl groups on the surface of NG. These bonded $\mathrm{Mn}^{2+}$ ions not only make NG lose reactivity for further condensation and carbonization, but also prevent the grain growth and agglomeration of the particles of NG. Therefore, the Mn(II)-NGQDs show well dispersed QDs with uniform size and shape, and exhibit a high QY than that of NG. It is notable that, compared to $\mathrm{Mn}^{2+}$, other metal ions (such as $\mathrm{Fe}^{2+}, \mathrm{Co}^{2+}, \mathrm{Ni}^{2+}, \mathrm{Mg}^{2+}, \mathrm{Zn}^{2+}, \mathrm{Ba}^{2+}, \mathrm{Ag}^{+}$and $\mathrm{Ca}^{2+}$ ) do not display such confinement effect to control the shape and grain growth of NG. TEM images of NG doping with other metal ions display similar morphology to pure NG, some large irregular sheets and small QDs can be observed (Fig. S6, ESI†). All of these M-NG display weaker fluorescent emission than Mn(II)-NGQDs. This confirms our conjecture and indicates that $\mathrm{Mn}^{2+}$ plays a key role in the synthesis of Mn(II)-NGQDs with enhanced fluorescent properties. 


\section{Detection of $\mathrm{Hg}^{2+}$ ion}

The surface characterization of Mn(II)-NGQDs clearly shows the feasibility of application as a fluorescent probe for metal ions detection, due to the homogeneous size distribution and excellent stable fluorescence properties. In this work, HMTA solution was chosen as the buffer to detect $\mathrm{Hg}$ (II) since it has been widely used in literature. ${ }^{45}$ Fig. 6 a shows the fluorescence response of $\mathrm{Mn}$ (II)-NGQDs in the presence and absence of $4 \times$ $10^{-6} \mathrm{~mol} \mathrm{~L}^{-1} \mathrm{Hg}^{2+}$ in different $\mathrm{pH}$ values. From Fig. 6a, it can be observed that the fluorescence intensity of Mn(II)-NGQDs displays a remarkably quenching effect with the addition of $\mathrm{Hg}^{2+}$ in a $\mathrm{pH}$ range of 5.5 to 8.7. Moreover, the $\mathrm{pH}$ value of the solution affects not only the fluorescence intensity of $\mathrm{Mn}$ (II)NGQDs but also the quenching efficiency. The fluorescence intensity of Mn(II)-NGQDs and quenching efficiency increase rapidly when the $\mathrm{pH}$ value increase from 5.5 to 8.0, and reach the maximum at the $\mathrm{pH}=7.35$ (Fig. 6a). However, an obvious decrease in quenching efficiency is observed when the $\mathrm{pH}$ value is higher than 7.35. Thus, it is clear that the quenching efficiency will decay in the acidic or alkaline conditions, and it is easier for $\mathrm{Hg}^{2+}$ ions to combine with Mn(II)-NGQDs and form a stable complex in neutral solution, which may be due to the weak protonated process of functional groups in the $\mathrm{Mn}$ (II)NGQDs. Considering the highest quenching efficiency, the following experimental conditions are all set in a pH of 7.35.

To discuss the sensitivity of Mn(II)-NGQDs as fluorescent probe for $\mathrm{Hg}^{2+}$ detection, the emission spectra of Mn(II)-NGQDs $\left(\lambda_{\text {ex }}=370 \mathrm{~nm}\right)$ in the presence of different concentrations of
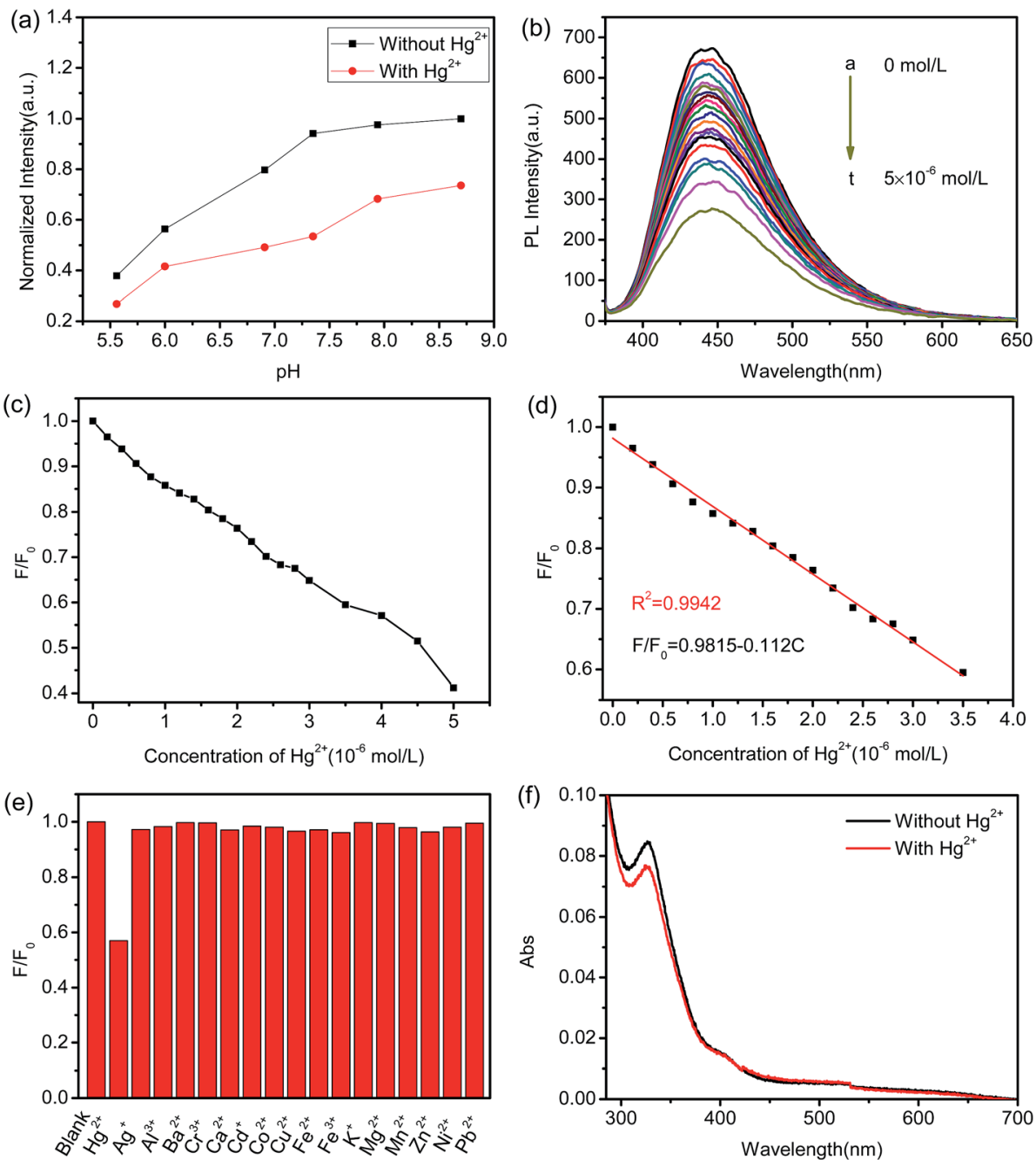

Fig. 6 (a) Fluorescence responses of $\mathrm{Mn}(\mathrm{II})-\mathrm{NGQDs}$ to different $\mathrm{pH}$ value of HMTA buffer under the absence and presence of $4 \times 10^{-6}$ mol $\mathrm{L}^{-1}$ $\mathrm{Hg}^{2+}$ ions; (b) emission spectra $\left(\lambda_{\mathrm{ex}}=370 \mathrm{~nm}\right)$ of $\mathrm{Mn}(\mathrm{II})-\mathrm{NGQDs}$ in the presence of different concentrations of $\mathrm{Hg}^{2+}\left(0-5.0 \times 10^{-6} \mathrm{~mol} \mathrm{~L}^{-1}\right)$ in HMTA buffer solution (pH = 7.35). (a) $0 \times 10^{-6} \mathrm{~mol} \mathrm{~L}^{-1}$, (b) $0.2 \times 10^{-6} \mathrm{~mol} \mathrm{~L}^{-1}$, (c) $0.4 \times 10^{-6} \mathrm{~mol} \mathrm{~L}^{-1}$, (d) $0.6 \times 10^{-6} \mathrm{~mol} \mathrm{~L}^{-1}$, (e) $0.8 \times$ $10^{-6} \mathrm{~mol} \mathrm{~L}^{-1}$, (f) $1.0 \times 10^{-6} \mathrm{~mol} \mathrm{~L}-1$, (g) $1.2 \times 10^{-6} \mathrm{~mol} \mathrm{~L}^{-1}$, (h) $1.4 \times 10^{-6} \mathrm{~mol} \mathrm{~L}^{-1}$, (i) $1.6 \times 10^{-6} \mathrm{~mol} \mathrm{~L}^{-1}$, (j) $1.8 \times 10^{-6} \mathrm{~mol} \mathrm{~L}^{-1}$, (k) $2.0 \times$ $10^{-6} \mathrm{~mol} \mathrm{~L}^{-1}$, (l) $2.2 \times 10^{-6} \mathrm{~mol} \mathrm{~L}^{-1}$, (m) $2.4 \times 10^{-6} \mathrm{~mol} \mathrm{~L}^{-1}$, (n) $2.6 \times 10^{-6} \mathrm{~mol} \mathrm{~L}^{-1}$, (o) $2.8 \times 10^{-6} \mathrm{~mol} \mathrm{~L}^{-1}$, (p) $3.0 \times 10^{-6} \mathrm{~mol} \mathrm{~L}-1,(\mathrm{q}) 3.5 \times$ $10^{-6} \mathrm{~mol} \mathrm{~L}^{-1}$, (r) $4.0 \times 10^{-6} \mathrm{~mol} \mathrm{~L}^{-1}$, (s) $4.5 \times 10^{-6} \mathrm{~mol} \mathrm{~L}^{-1}$, (t) $5.0 \times 10^{-6} \mathrm{~mol} \mathrm{~L}^{-1}$; (c) the relationship between the $F / F_{0}$ and $\mathrm{Hg}^{2+} \mathrm{concentrations}$ (c: $0-5.0 \times 10^{-6} \mathrm{~mol} \mathrm{~L}^{-1}$ ); (d) plots of intensity ratio of $F / F_{0}$ versus the concentrations of $\mathrm{Hg}^{2+}\left(0-3.5 \times 10^{-6} \mathrm{~mol} \mathrm{~L}^{-1}\right)$; (e) fluorescence responses of $\mathrm{Mn}(\Perp)-\mathrm{NGQDs}$ to the different metal ions in HMTA buffer solution $(\mathrm{pH}=7.35)$. The concentration of each metal ion is $4.0 \times 10^{-6} \mathrm{~mol} \mathrm{~L}^{-1}$. $F_{0}$ and $F$ correspond to the fluorescence intensities of $M n(॥)-N G Q D s$ at $440 \mathrm{~nm}$ with the $370 \mathrm{~nm}$ excitation wavelength in the absence and presence of metal ions, respectively; (f) the UV absorption spectra of $\mathrm{Mn}(I)-\mathrm{NGQDs}$ without $\mathrm{Hg}^{2+}$ and in the presence of $\mathrm{Hg}^{2+}\left(4.0 \times 10^{-6} \mathrm{~mol} \mathrm{~L}^{-1}\right)$. 
$\mathrm{Hg}^{2+}$ ion (in the range of 0 to $5.0 \times 10^{-6} \mathrm{~mol} \mathrm{~L}^{-1}$ ) were recorded and shown in Fig. 6b. A gradually decrease emission intensity at $443 \mathrm{~nm}$ is observed with the increase concentration of $\mathrm{Hg}^{2+}$ ion, implying that the fluorescence of Mn(II)-NGQDs solution is sensitive to $\mathrm{Hg}^{2+}$. As shown in Fig. 6c, the quenching efficiency $\left(F / F_{0}\right)$ displays a good linear response to the concentration of $\mathrm{Hg}^{2+}$ in the range of 0 to $3.5 \times 10^{-6} \mathrm{~mol} \mathrm{~L}^{-1}$ (Fig. 6d). The linear equation is calculated to be $F_{0} / F=0.9815-0.112\left[\mathrm{Hg}^{2+}\right]\left(R^{2}=\right.$ 0.9942 ), where $F_{0}$ and $F$ are emission intensities at $443 \mathrm{~nm}$ in the absence and presence of $\mathrm{Hg}^{2+}$ ion, respectively. Under this experiment condition, the limit of detection (LOD) for $\mathrm{Hg}^{2+}$ is calculated to be $3.4 \times 10^{-8} \mathrm{~mol} \mathrm{~L}^{-1}$ by the $3 \delta / S(\delta$ is the standard deviation of the lowest signal and $S$ is the slope of linear calibration plot), which is much lower than most of other reported of common fluorescent probes (see Table S2, ESI $\dagger$ ). ${ }^{46-50}$

The selectivity of the Mn(II)-NGQDs toward $\mathrm{Hg}^{2+}$ was also explored. Different metal ions such as $\mathrm{Cu}^{2+}, \mathrm{Mn}^{2+}, \mathrm{Ag}^{+}, \mathrm{Pb}^{2+}, \mathrm{K}^{+}$, $\mathrm{Ba}^{2+}, \mathrm{Zn}^{2+}, \mathrm{Co}^{2+}, \mathrm{Hg}^{2+}, \mathrm{Al}^{3+}, \mathrm{Fe}^{2+}, \mathrm{Fe}^{3+}, \mathrm{Ni}^{2+}, \mathrm{Mg}^{2+}, \mathrm{Cd}^{2+}$ and $\mathrm{Hg}^{2+}$ ions were added into the probe solution respectively, and the solution was analyzed after incubation of $10 \mathrm{~min}$. The results in Fig. 6e manifest that these metal ions except $\mathrm{Hg}^{2+}$ ion have almost no interference on the fluorescence intensity of $\mathrm{Mn}$ (II)NGQDs, the fluorescence intensity is apparently quenched only by $\mathrm{Hg}^{2+}$ ion. Therefore, the fluorescence sensor based on $\mathrm{Mn}$ (II)NGQDs shows a higher selectivity for $\mathrm{Hg}^{2+}$ detection over the other metal ions. Similarly, the effects of non buffer (Milli-Q water) on the detection of $\mathrm{Hg}^{2+}$ were performed, the results show that Mn(II)-NGQDs also exhibit a highly selective and sensitive capability to $\mathrm{Hg}^{2+}$ in Milli-Q water (Fig. S7, ESI†), which is similar to that in the HMTA buffer.

To clarify whether the fluorescence quenching is a static or dynamic quenching process, the fluorescence decay characterization was conducted. Fig. S8 (ESI $\dagger$ ) show the fluorescence decay profile of $\mathrm{Mn}$ (II)-NGQDs in the absence and presence of $\mathrm{Hg}^{2+}$ ions, respectively. The fluorescence decay profile of $\mathrm{Mn}$ (II)NGQDs follows a single exponential fitting that indicated the presence of only one emitting species with lifetimes. However, the fluorescence decay profile of NG follows a tri-exponential fitting (Fig. S8, Table S3, ESI†), which indicates the presence of three emitting species with different lifetimes. It is possible due to the mixture of NG with nanosheets and QDs, which resulting a complex different lifetimes emission. ${ }^{51}$ The average lifetime of Mn(II)-NGQDs is $7.58 \mathrm{~ns}$, which is shorter than that of NG (8.88 ns) and also support our point that the doping with $\mathrm{Mn}^{2+}$ can influence the morphology of NG. The lifetime data in Table S3 (ESI $\dagger$ ) shows that the average lifetime of Mn(II)-NGQDs have not significantly change with the concentration increase of $\mathrm{Hg}^{2+}$ ions. It is indicated that the static quenching takes place during complex formation between $\mathrm{Hg}^{2+}$ ions and $\mathrm{Mn}$ (II)NGQDs. ${ }^{52,53}$

The quenching effect can be attributed to the chelating reaction between the functional groups (such as carboxyl, hydroxyl and amino groups) on the surface of Mn(II)-NGQDs and $\mathrm{Hg}^{2+}$ ion, which can decelerate the radiative recombination of the exciton of $\mathrm{n} \rightarrow \pi^{*}$ transition through an effective electron transfer process, leading to the fluorescent quenching. ${ }^{.5}$ In order to further understand the binding between Mn(II)-NGQDs and $\mathrm{Hg}^{2+}$, the UV absorption spectra of Mn(II)-NGQDs without $\mathrm{Hg}^{2+}$ and in the presence of $\mathrm{Hg}^{2+}\left(4.0 \times 10^{-6} \mathrm{~mol} \mathrm{~L}^{-1}\right)$ were recorded (Fig. 6f). The absorption peaks at $340 \mathrm{~nm}$ (due to the $\mathrm{n}$ $\rightarrow \pi^{*}$ transition) for Mn(II)-NGQDs is remarkably declined in the presence of $\mathrm{Hg}^{2+}$, demonstrating the surface states of the quantum dots can be influenced by the binding of $\mathrm{Mn}$ (II)NGQDs with $\mathrm{Hg}^{2+}$. This means that compared to other metal ions, $\mathrm{Hg}^{2+}$ ion shows a more powerful affinity and faster chelating toward the functional groups on the surface of the Mn(II)-NGQDs. In addition, the photoinduced electron transfer from conduction band to the state of $\mathrm{Hg}^{2+}$ would be located between the conduction band and valence band of $\mathrm{Mn}$ (II)NGQDs, causing the fluorescence quenching. These results also indicate that the fluorescence quenching of Mn(II)-NGQDs by $\mathrm{Hg}^{2+}$ is a static quenching process.

\section{Cellular toxicity and cell fluorescent imaging}

In order to evaluate the potential biological imaging application of Mn(II)-NGQDs, the biocompatibility of Mn(II)-NGQDs was evaluated via incubating HepG2 cells with different concentrations of Mn(II)-NGQDs for 4 and $24 \mathrm{~h}$, respectively. The survival quantity of HepG2 cells was calculated based on MTT cellviability assay. As show in Fig. 7, the cell viabilities of HepG2 cells are all close to $100 \%$ in the tested period with the concentration of $\mathrm{Mn}$ (II)-NGQDs from 0 to $300 \mu \mathrm{g} \mathrm{mL} \mathrm{L}^{-1}$, and there are almost no changes of the cells viability values of HepG2 cells incubated by Mn(II)-NGQDs with various concentrations for 4 and $24 \mathrm{~h}$. It is obvious that the Mn(II)-NGQDs have no cytotoxicity to HepG2 cells. In addition, the zeta potential of Mn(II)-NGQDs and NG was also explored (Fig. S9, ESI†). Compared with NG $(-15.2 \mathrm{eV}), \mathrm{Mn}(\mathrm{II})-\mathrm{NGQDs}$ exhibit a more negative potential value $(-19.7 \mathrm{eV})$, which indicates that $\mathrm{Mn}$ (II)NGQDs will be more stable and efficiently internalized by cells.

The utilization of Mn(II)-NGQDs in cellular imaging was also investigated by confocal laser scanning microscopy (CLSM) observation. As shown in Fig. 8, the obvious blue fluorescent signal can be observed in the cytoplasm of Raw264.7 (Fig. 8a $\mathrm{a}_{1}$ )

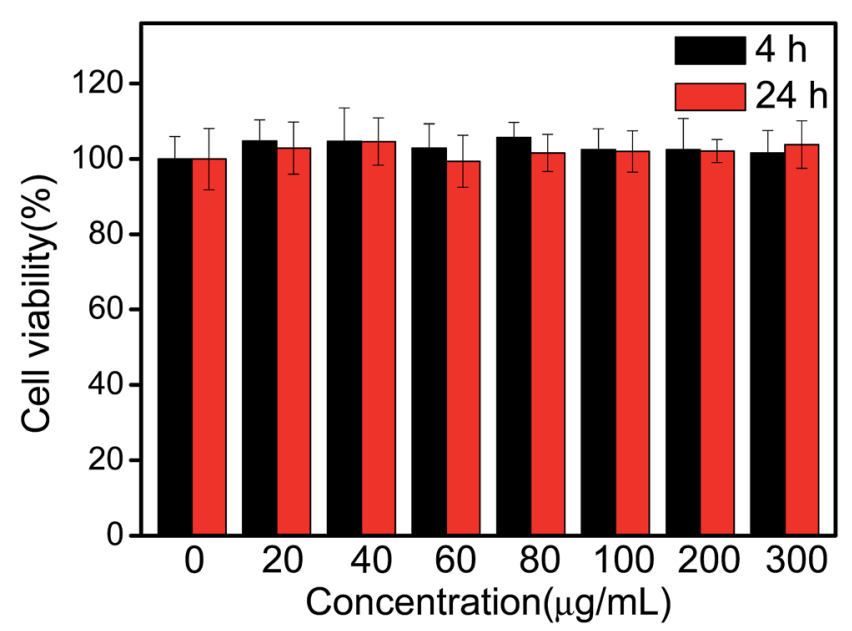

Fig. 7 Cell viability of HepG2 cells after incubation with Mn(॥)-NGQDs $\left(0-300 \mu \mathrm{g} \mathrm{mL}^{-1}\right)$ for 4 and $24 \mathrm{~h}$, respectively. 

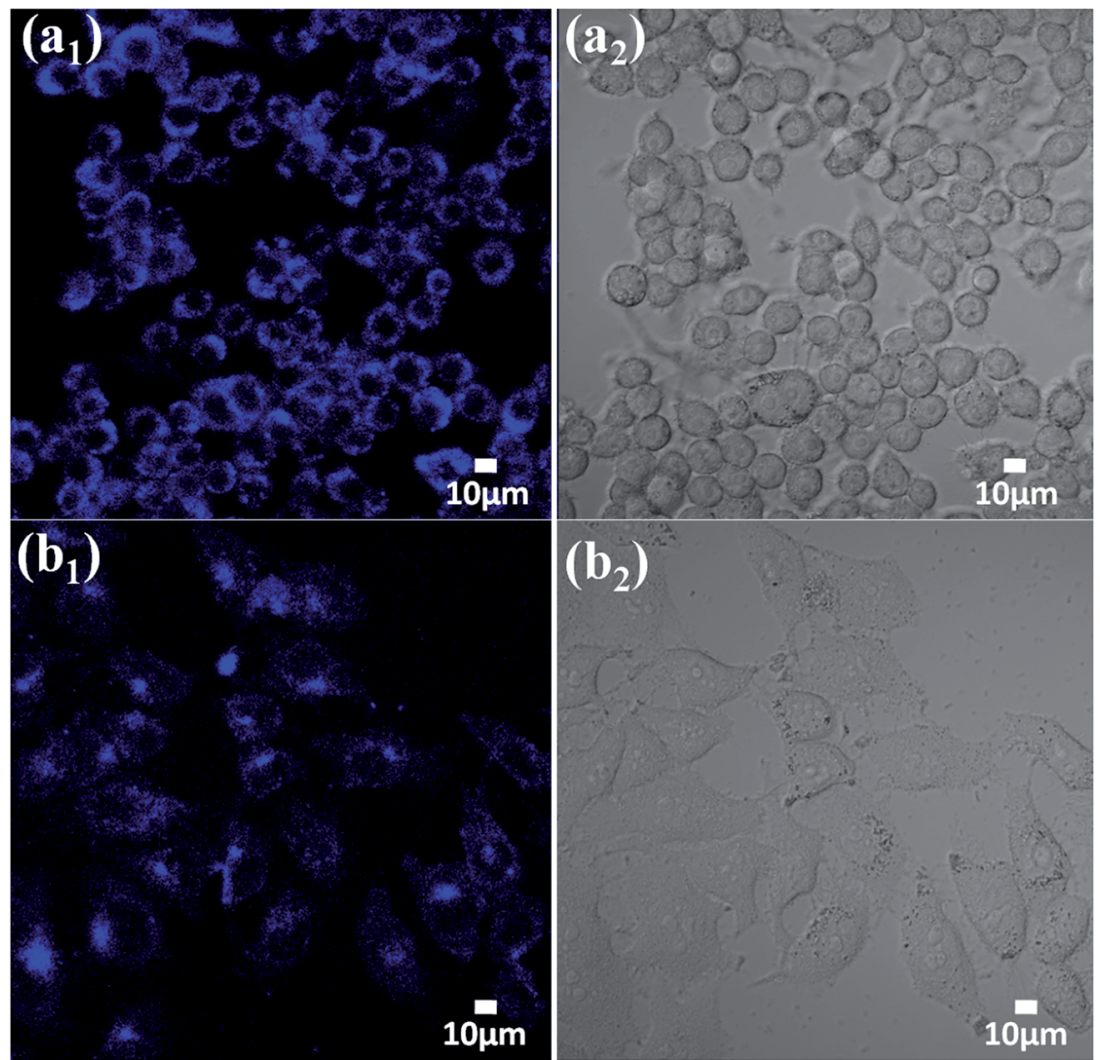

Fig. 8 CLSM images and bright field of Raw264.7 mouse macrophages $\left(a_{1} ; a_{2}\right)$ and HepG2 human liver cancer cells $\left(b_{1} ; b_{2}\right)$ incubated with Mn(I)NGQDs $\left(40 \mu \mathrm{g} \mathrm{mL}^{-1}\right)$ for $3 \mathrm{~h}$ by excitation at $405 \mathrm{~nm}$.

and HepG2 cells (Fig. 8 $\mathrm{b}_{1}$ ) incubated with Mn(II)-NGQDs at a concentration of $40 \mu \mathrm{g} \mathrm{mL} \mathrm{m}^{-1}$ for $3 \mathrm{~h}$, indicating that the $\mathrm{Mn}$ (II)NGQDs can be efficiently internalized by Raw264.7 and HepG2 cells and facilely enter into the cells for efficiency cell imaging. ${ }^{55,56}$ Moreover, both the Raw264.7 (Fig. 8a a $_{2}$ and HepG2 cells (Fig. $8 \mathrm{~b}_{2}$ ) incubated with Mn(II)-NGQDs still kept their normal morphology and strongly adhered onto cell plates, revealing the good biocompatibility of Mn(II)-NGQDs. Thus, the Mn(II)-NGQDs can be served as an efficient and non-toxic and fluorescence bioimaging probe for various biomedical applications.

\section{Conclusion}

In conclusion, we have demonstrated a simple and feasible synthesis strategy to prepare fluorescent Mn(II)-NGQDs through hydrothermal carbonization of glycine and sodium citrate with $\mathrm{Mn}^{2+}$ as modifier. The resulted Mn(II)-NGQDs display the morphology with uniform size and good dispersion, and show enhanced fluorescent compared with NG and NG doped with other common metal ions. The Mn(II)-NGQDs can be utilized directly as a fluorescent probe for highly sensitive and selective detection of $\mathrm{Hg}^{2+}$ ions. Confinement effect and radiative recombination mechanism were used to explained the fluorescence enhancement and quenching, respectively. The watersoluble Mn(II)-NGQDs also show low cytotoxicity, superior brightness and high photostability for fluorescence live cell imaging. This work may provide a strategic approach for preparing high-quality fluorescent GQDs to meet the requirement of multifunctional application.

\section{Conflicts of interest}

There are no conflicts to declare.

\section{Acknowledgements}

This work was financially supported by the National Natural Science Foundation of China (No. 51564009, 51468011) and the Natural Science Foundation of Guangxi Province (No. 2015GXNSFDA139035).

\section{References}

1 J. Liu, H. Xu, Y. Xu, Y. Song, J. Lian, Y. Zhao, L. Wang, L. Huang, H. Ji and H. Li, Appl. Catal., B, 2017, 207, 429-437.

2 A. Subramanian, Z. Pan, G. Rong, H. Li, L. Zhou, W. Li, Y. Qiu, Y. Xu, Y. Hou, Z. Zheng and Y. Zhang, J. Power Sources, 2017, 343, 39-46.

3 D. H. Kim and T. W. Kim, Nano Energy, 2017, 32, 441-447.

4 L. Wang, W. Li, B. Wu, Z. Li, D. Pan and M. Wu, Chem. Eng. J., 2017, 309, 374-380.

5 L. Chen, G. Yang, P. Wu and C. Cai, Biosens. Bioelectron., 2017, 96, 294-299. 
6 L. Li, G. Wu, G. Yang, J. Peng, J. Zhao and J. J. Zhu, Nanoscale, 2013, 5, 4015-4039.

7 T. F. Yeh, W. L. Huang, C. J. Chung, I. T. Chiang, L. C. Chen, H. Y. Chang, W. C. Su, C. Cheng, S. J. Chen and H. Teng, J. Phys. Chem. Lett., 2016, 7, 2087-2092.

8 Y. Zhang, H. Gao, J. Niu and B. Liu, New J. Chem., 2014, 38, 4970-4974.

9 T. F. Yeh, C. Y. Teng, S. J. Chen and H. Teng, Adv. Mater., 2014, 26, 3297-3303.

10 M. Zhang, L. Bai, W. Shang, W. Xie, H. Ma, Y. Fu, D. Fang, H. Sun, L. Fan, M. Han, C. Liu and S. Yang, J. Mater. Chem., 2012, 22, 7461.

11 A. H. Castro Neto, F. Guinea, N. M. R. Peres, K. S. Novoselov and A. K. Geim, Rev. Mod. Phys., 2009, 81, 109-162.

12 Z. Fan, S. Li, F. Yuan and L. Fan, $R S C A d v .$, 2015, 5, 1977319789.

13 Y. Zhou, X. Jing and Y. Chen, J. Mater. Chem. B, 2017, 5, 6451-6470.

14 B. Shi, Y. Su, L. Zhang, M. Huang, X. Li and S. Zhao, Nanoscale, 2016, 8, 10814-10822.

15 A. Muthurasu, P. Dhandapani and V. Ganesh, New J. Chem., 2016, 40, 9111-9124.

16 Q. Zhuang, Y. Wang and Y. Ni, Luminescence, 2016, 31, 746753.

17 T. V. Tam, N. B. Trung, H. R. Kim, J. S. Chung and W. M. Choi, Sens. Actuators, B, 2014, 202, 568-573.

18 T. Alizadeh and M. Shokri, Sens. Actuators, B, 2016, 222, 728734.

19 Y. Dong, J. Shao, C. Chen, H. Li, R. Wang, Y. Chi, X. Lin and G. Chen, Carbon, 2012, 50, 4738-4743.

20 W. Zhang and J. Gan, Appl. Surf. Sci., 2016, 372, 145-151.

21 H. X. Zhao, Y. C. Wang, L. Y. Zhang and M. Wang, New J. Chem., 2015, 39, 98-101.

22 S. Yang, J. Sun, C. Zhu, P. He, Z. Peng and G. Ding, Analyst, 2016, 141, 1052-1059.

23 U. Baruah and D. Chowdhury, Nanotechnology, 2016, 27, 145501.

24 S. Kundu, R. M. Yadav, T. N. Narayanan, M. V. Shelke, R. Vajtai, P. M. Ajayan and V. K. Pillai, Nanoscale, 2015, 7, 11515-11519.

25 H. Xu, S. Zhou, L. Xiao, Q. Yuan and W. Gan, RSC Adv., 2016, 6, 36554-36560.

26 X. Zhu, G. Wu, N. Lu, X. Yuan and B. Li, J. Hazard. Mater., 2017, 324, 272-280.

27 S. Vempati, A. Celebioglu and T. Uyar, Nanoscale, 2015, 7, 16110-16118.

28 G. S. Kumar, R. Roy, D. Sen, U. K. Ghorai, R. Thapa, N. Mazumder, S. Saha and K. K. Chattopadhyay, Nanoscale, 2014, 6, 3384-3391.

29 S. H. Jin, D. H. Kim, G. H. Jun, S. H. Hong and S. Jeon, ACS Nano, 2013, 7, 1239-1245.

30 K. Paek, H. Yang, J. Lee, J. Park and B. J. Kim, ACS Nano, 2014, 8, 2848-2856.
31 Z. Gan, H. Xu and Y. Hao, Nanoscale, 2016, 8, 7794-7807.

32 C. A. T. Toloza, S. Khan, R. L. D. Silva, E. C. Romani, D. G. Larrude, S. R. W. Louro, F. L. Freire and R. Q. Aucélio, Microchem. J., 2017, 133, 448-459.

33 D. Yu, X. Zhang, Y. Qi, S. Ding, S. Cao, A. Zhu and G. Shi, Sens. Actuators, B, 2016, 235, 394-400.

34 C. Han, H. Xu, R. Wang, K. Wang, Y. Dai, Q. Liu, M. Guo, J. Li and K. Xu, J. Mater. Chem. B, 2016, 4, 5798-5802.

35 X. Guo, C. F. Wang, Z. Y. Yu, L. Chen and S. Chen, Chem. Commun., 2012, 48, 2692-2694.

36 T. F. Yeh, F. F. Chan, C. T. Hsieh and H. Teng, J. Phys. Chem. C, 2011, 115, 22587-22597.

$37 \mathrm{H}$. Abdolmohammad-Zadeh and E. Rahimpour, Sens. Actuators, B, 2016, 225, 258-266.

38 B. Karimi and B. Ramezanzadeh, J. Colloid Interface Sci., 2017, 493, 62-76.

39 Z. Yan, X. Qu, Q. Niu, C. Tian, C. Fan and B. Ye, Anal. Methods, 2016, 8, 1565-1571.

40 L. Li, L. Li, C. Wang, K. Liu, R. Zhu, H. Qiang and Y. Lin, Microchim. Acta, 2014, 182, 763-770.

41 J. Gliniak, J. H. Lin, Y. T. Chen, C. R. Li, E. Jokar, C. H. Chang, C. S. Peng, J. N. Lin, W. H. Lien, H. M. Tsai and T. K. Wu, ChemSusChem, 2017, 10, 3260-3267.

42 E. Yazici, S. Yanik and M. B. Yilmaz, Carbon, 2017, 111, 822827.

43 Z. X. Gan, S. J. Xiong, X. L. Wu, C. Y. He, J. C. Shen and P. K. Chu, Nano Lett., 2011, 11, 3951-3956.

44 Y. Liu, C. Y. Liu and Y. Liu, Appl. Surf. Sci., 2011, 257, 55135518.

45 P. Hou, Y. Long, J. Zhao, J. Wang and F. Zhou, Spectrochim. Acta, Part A, 2012, 86, 76-79.

46 Z. Xiaoyan, L. Zhangyi and L. Zaijun, Spectrochim. Acta, Part $A, 2017,171,415-424$.

47 X. Zuo, H. Zhang, Q. Zhu, W. Wang, J. Feng and X. Chen, Biosens. Bioelectron., 2016, 85, 464-470.

48 Z. Wu, M. Feng, X. Chen and X. Tang, J. Mater. Chem. B, 2016, 4, 2086-2089.

49 R. Zhang and W. Chen, Biosens. Bioelectron., 2014, 55, 83-90.

50 J. He, H. Zhang, J. Zou, Y. Liu, J. Zhuang, Y. Xiao and B. Lei, Biosens. Bioelectron., 2016, 79, 531-535.

51 S. Barman and M. Sadhukhan, J. Mater. Chem. C, 2012, 22, 21832.

52 Y. Zhang, P. Cui, F. Zhang, X. Feng, Y. Wang, Y. Yang and X. Liu, Talanta, 2016, 152, 288-300.

53 Y. Wang, Q. Chang and S. Hu, Sens. Actuators, B, 2017, 253, 928-933.

54 X. Mao, H. Su, D. Tian, H. Li and R. Yang, ACS Appl. Mater. Interfaces, 2013, 5, 592-597.

55 Z. Fan, Y. Li, X. Li, L. Fan, S. Zhou, D. Fang and S. Yang, Carbon, 2014, 70, 149-156.

56 F. Yuan, L. Ding, Y. Li, X. Li, L. Fan, S. Zhou, D. Fang and S. Yang, Nanoscale, 2015, 7, 11727-11733. 